\title{
Novel Fruit Juice Based Nutraceutical Formulation with Probiotic and Cholesterol Reduction Properties
}

\author{
Ajitha S. Nair ${ }^{1}$, Aparna V. Dubhashi ${ }^{2^{*}}$ \\ ${ }^{1}$ Department of Microbiology, S.I.W.S. College, University of Mumbai, Mumbai, India \\ ${ }^{2}$ Department of Microbiology, G.N. Khalsa College, Autonomous Institution, Mumbai, India \\ Corresponding Author: aparna.dubhashi@gnkhalsa.edu.in Tel.: +91-22- 24096234
}

Available online at: www.isroset.org

Received: 01/Jul/2019, Accepted: 22/Aug/2019, Online: 31/Aug/2019

\begin{abstract}
This work encompasses the use of a sporulating probiotic culture, Brevibacillus borstelensis, to prepare a nutraceutical product with a mixed fruit juice as a carrier for the culture. Lyophilization of the formulation was carried out using different dehydrating agents, pectin, ascorbic acid, gelatin, gum Arabic and maltodextrin in specific permissible concentrations. Pectin gave the best results in terms of consistency and appearance of the nutraceutical powder, hence was used in the final formulation. The nutraceutical powder was then analysed for its shelf life, physical, chemical and nutritional profile. It was also tested for heavy metal contaminants, antibacterial activity and cholesterol reduction capability. Microbiological safety of the formulation was verified according to FSSAI manual. Encouraging results were obtained from the analyses. Lyophilization helped retain the nutrients of the fruits as well as improved the keeping quality of the formulation. The novel probiotic containing nutraceutical powder prepared could be helpful to lactose intolerant population. Its cholesterol reduction property could be beneficial to hypercholesteraemic individuals.
\end{abstract}

\section{Keywords: Nutraceutical, probiotic, Brevibacillus borstelensis, mixed fruit juice, cholesterol reduction}

\section{INTRODUCTION}

Food can be used as prophylactic and therapeutic agent. If it is natural and non-synthetic it has more advantages. The term Nutraceutical is a hybrid of nutrition and pharmaceutical and was introduced in 1989 by Stephen L. DeFelice. It can be defined as "Food, or parts of food, that provide medical or health benefits, including the prevention and treatment of disease" [1]. A lot of work is being carried out to prove the benefit of nutraceuticals like antioxidants, vitamins, amino acids, phytochemicals, and polyunsaturated fatty acids in foods which help to improve the immune system [2].

Fruits are perishable and available only seasonally. Food industries therefore process fruits to increase their shelf life. However, these processed fruits no longer retain the nutritive value of the original fruit. Hence nutraceutical products which claim to retain the nutritive value of these fruits must process them to minimize this loss.

Pomegranates have phytochemicals like polyphenols, tannins like punicalagins [3], protein, minerals like $\mathrm{Ca}, \mathrm{Mg}$, $\mathrm{P}, \mathrm{Fe}, \mathrm{Na}, \mathrm{K}, \mathrm{Cu}, \mathrm{S}, \mathrm{Cl}$ and vitamins like carotene, thiamine, riboflavin, nicotinic acid, vitamin $\mathrm{C}$ and pectin which act as antioxidants and reduce blood pressure, and are helpful in preventing breast cancer [4]. Pineapples contain the active constituent bromelain which has antidiabetic, antioxidant, and anti-hyperlipidaemic properties [5]. Citrus fruits, rich in vitamins, healthy antioxidants and flavonoids are beneficial for prevention of cardiovascular disease [6].

Dehydration is one of the methods to make fruits available all year round and also increase their shelf life by reducing the $a_{w}$ of fruits [7]. The methods include drying in hot air, osmotic dehydration, frying, drying in a microwave and freeze drying. Drying at high temperatures can destroy many of the nutrients in a fruit which are heat labile, so drying in hot air, frying and drying in a microwave were all avoided in the current work.

Fruit juices contain large amounts of simple sugars, such as glucose, fructose and sucrose, which make them very sticky during spray drying. Maltodextrins and gum Arabic are the most often used for fruit juices to improve texture and as drying agents [8].

Lyophilization or Freeze drying is the removal of water from a substance by sublimation. Freeze dried fruits maintain colours better than fruits dried by other methods, thus 
indicating lesser loss of nutrients. Freeze drying allows the retention of ascorbic acid when conducted at low temperatures [9].

Probiotics can reduce cholesterol. It was observed that consumption of Bifidobacterium milk led to reduction in triglyceride, low-density lipid, and total cholesterol. [10] Another study showed a significant decrease in blood cholesterol when fermented milk containing L. acidophilus was consumed during controlled clinical trials. [11] A metaanalysis study review involving probiotics and serum lipids which tested strains of Lactobacillus acidophilus, Bifidobacterium lactis, Lactobacillus plantarum and Lactobacillus helveticus, found that they reduced total cholesterol by an average of $7.8 \mathrm{mg} / \mathrm{dL}$ and LDL cholesterol by $7.3 \mathrm{mg} / \mathrm{dL}$ [12].

Rest of the paper is organized as follows Section II includes Related work. Section III is Methodology which is further divided into subsections of Formulation and Analysis of the nutraceutical. Section IV contains Results and Discussion. Section V concludes the research work.

In the present study, a fruit juice-based nutraceutical powder was formulated with a probiotic Brevibacillus borstelensis (Gen Bank accession number MK156349) [13]. Being a non-dairy product, it can be used by lactose intolerant people. By testing the shelf life of the probiotic, studying the nutrition profile, antibacterial activity, chemical parameters, heavy metal contamination, cholesterol reduction ability and microbiological safety of the formulation, we will be arriving at a safe, novel nutraceutical having the benefits of natural fruit ingredients as well as the probiotic culture, which has a longer shelf life.

\section{RELATED WORK}

Dairy products have been extensively used as carriers for probiotic cultures especially Lactic acid bacteria. However, there is an increased demand for non-dairy based probiotic supplements due to vegetarianism; cholesterol content of milk, lactose intolerance, milk allergy and other factors [14]. A number of studies have been conducted using fruit juices as a medium for probiotic growth and viability. [15-17] Food matrices like fruits and vegetables are being used as potential media as they contain beneficial nutrients and are an ideal carrier for probiotics. Several types of probiotic fruits and vegetable products have been developed and marketed, such as fruits and vegetables juices, dried fruits, fermented vegetables and deserts. Many probiotic strains, mainly species of Lactobacillus and Bifidobacteria have been used in the development of juice products, including pomegranate, orange, cashew apple, tomato, cabbage, beet and carrot juices [18]. Novel probiotics can be added to nutraceutical formulations, which have some beneficial effect on human health. [19]

\section{METHODOLOGY}

\section{1] Formulation of the nutraceutical}

Fruits orange, sweet lime, pomegranate and pineapple were washed with water, blanched and used for preparing mixed fruit juice. It was then strained through sterile muslin cloth. Aseptic conditions were maintained during juice extraction, which was performed in a biosafety cabinet.

\section{Selection of the appropriate dehydrating agent:}

To select the dehydrating agent only pineapple juice was lyophilized, since pineapple has the highest sugar content among the selected fruits and the agent which would give a good texture to it was also expected to do the same for the mixed fruit juice. It was dispensed in 5 separate flasks, each was mixed with a different dehydrating agent like pectin, ascorbic acid, gum Arabic, gelatin and maltodextrin. The probiotic Brevibacillus borstelensis was inoculated to a final density of $10^{10}$ spores / $\mathrm{ml}$. These were then lyophilized. The consistency and appearance of the juice powder obtained after lyophilization were compared and the one giving the best results was used for the final formulation.

Formulation of the nutraceutical containing probiotic: $500 \mathrm{ml}$ of the mixed fruit juice was inoculated with $10 \mathrm{ml}$ of spore suspension of Brevibacillus borstelensis to a final density of $10^{10}$ spores / $\mathrm{ml}$. Sterile pectin solution at a final concentration of 5\% was mixed with the juice as the selected dehydrating agent. The flask was kept on a shaker maintained at $5^{0} \mathrm{C}$ for 2 hours. The sample was frozen at a temperature of $-23^{\circ} \mathrm{C}$ for 12 hours. Lyophilization was carried out at $8-10 \mathrm{mT}$ Torr pressure and $-86^{\circ} \mathrm{C}$ temperature for 96 hours to obtain the juice in a powder form. The viability of probiotic culture was tested by spread plate technique before and after lyophilization.

\section{2] Analysis of the Nutraceutical:}

i. Shelf life of the probiotic:

Viable count of the probiotic culture in the nutraceutical preparation was carried out at monthly intervals for up to 6 months after lyophilization. Counts were expressed as cfu per gm of the powder.

\section{ii. Antibacterial activity:}

The Agar well diffusion method using Mueller Hinton agar plates was performed [20]. Test cultures used were Bacillus cereus NCIM 2109, Bacillus subtilis 6633, Brevibacterium casei MCC 2029, Staphylococcus aureus, MRSA, Salmonella para typhi B, Salmonella abony and Escherichia coli $500 \mathrm{mg} / \mathrm{ml}, 250 \mathrm{mg} / \mathrm{ml}, \quad 125 \mathrm{mg} / \mathrm{ml}$ and $62.5 \mathrm{mg} / \mathrm{ml}$ concentrations of the nutraceutical powder were prepared using sterile saline. $50 \mu \mathrm{l}$ of each was added to the wells. Zones of inhibition around the wells were measured and expressed in mms after incubation at $37^{0} \mathrm{C}$ for 24 hours. 


\section{iii. Nutrition profile:}

The nutraceutical sample was analysed for energy content (EL/SOP/509), total fat (EL/SOP/502), cholesterol (AOAC 976.26), total carbohydrates (IS 1656:2007, RA 2012), protein (EL/SOP/549), vitamin C (IS 538: 1970 RA 2010) and fatty acid profile (AOAC 996.06)

\section{iv. Chemical parameters:}

Water activity (EL/SOP/ 530), Total soluble solids (TSS) using the refractometer, calibrated at $20^{\circ} \mathrm{C}$. [21], Colour value - Konica Minolta, CM 3600d [22], tapped bulk density USP 23, bulk density USP 23 [https://www.usp.org]

\section{Heavy Metal contaminants:}

The heavy metals like Arsenic, Lead, Mercury, Cadmium were estimated by EL/SOP/579.

pH: One gram of the sample was reconstituted in $100 \mathrm{ml}$ of neutralized distilled water and the $\mathrm{pH}$ was determined using $\mathrm{pH}$ meter.

Titratable acidity: One gram of the sample was reconstituted in $100 \mathrm{ml}$ of neutralized distilled water. $0.3 \mathrm{ml}$ of phenolphthalein indicator was added. The mixture was then titrated with $0.1 \mathrm{~N} \mathrm{NaOH}$ till the end point was reached i.e. $\mathrm{pH} 8.2$ [AOAC $17^{\text {th }}$ ed, 2000]

$\%$ acid $=[\mathrm{Vol}$ of $\mathrm{NaOH}] \times[\mathrm{N}$ of $\mathrm{NaOH}] \times[$ milliequivalent factor] x 100 / gram of sample

$1 \mathrm{~mL}$ of $0.1 \mathrm{~N} \mathrm{NaOH}$ equals Citric acid anhydrous - 0.0064 gm Tartaric acid - 0.0075 gm

$\%$ acid $=[\underline{\mathrm{ml} \text { of } \mathrm{NaOH}] \times 0.1 \times 0.0064 \times 100}$

(Citric acid) $1 \mathrm{gm}$

\section{v. Cholesterol reduction assay}

An invitro assay was performed to test the ability of the nutraceutical as well as the prospective probiotic bacterium Brevibacillus borstelensis to reduce cholesterol using Zaks method [https://www.protocolpedia.com].

The test solutions were prepared using de Man, Rogosa, and Sharpe broth (MRS) broth with $0.3 \%$ bile salt and $100 \mathrm{mcg} / \mathrm{ml}$ cholesterol, inoculated with the probiotic culture in one tube and the final nutraceutical product in another and incubated at $37^{\circ} \mathrm{C}$ for 24 hours. Reduction of cholesterol was estimated as per the above protocol.

\section{vi. Microbiological safety:}

The nutraceutical was analysed for the presence of aerobic mesophiles, coliforms, pathogens like Staphylococcus aureus, Salmonella species, Shigella species, Vibrio cholerae, Clostridium perfringens, yeast and moulds. [23]

\section{RESULT AND DISCUSSION}

\section{[1]. Formulation of the nutraceutical}

The weight of dry powder yield from $100 \mathrm{ml}$ of the pineapple juice after lyophilization differed with the dehydrating agent used (Table 1).

Maltodextrin, Gum Arabic, Gelatin and Ascorbic acid gave sticky lumps, difficult to remove from the glass containers. In terms of consistency, appearance and hygroscopic property, the sample with pectin gave the best results.

Table 1: Comparison of the pineapple juice powder prepared using different dehydrating agents

\begin{tabular}{|l|l|l|l|}
\hline $\begin{array}{l}\text { Dehydrating } \\
\text { agent }\end{array}$ & $\begin{array}{l}\text { Weight of } \\
\text { powder in } \\
\text { g from } \mathbf{1 0 0} \mathbf{~ m l} \\
\text { of juice }\end{array}$ & Colour & $\begin{array}{l}\text { Average count } \\
\text { of probiotic } \\
\text { cfu/g }\end{array}$ \\
\hline Maltodextrin & 29.92 & Brown & $5.8 \times 10^{10}$ \\
\hline Ascorbic acid & 8.99 & Yellow & $2.9 \times 10^{10}$ \\
\hline Gum Arabic & 23.61 & Light brown & $1.2 \times 10^{10}$ \\
\hline Pectin & 16.04 & Pale yellow & $3.03 \times 10^{10}$ \\
\hline Gelatin & 10.63 & Pale yellow & $4.8 \times 10^{10}$ \\
\hline
\end{tabular}

A one $\log$ cycle reduction in viability of Brevibacillus borstelensis was observed upon lyophilization from the original count of $1.08 \times 10^{11} \mathrm{cfu} / \mathrm{ml}$ before lyophilization. This indicates that the probiotic could tolerate the mixed fruit juice carrier as well as the lyophilization conditions well. In a similar study reported earlier, freeze-dried probiotic papaya juice powder did not show any log alteration in the number of probiotic organisms [24]. A probiotic beverage should possess a minimum viable count of $10^{6} \mathrm{cfu} / \mathrm{ml}$ [25].

Pectin was used as the dehydrating agent to prepare the final nutraceutical product. Many manufacturers use pectin as a functional fiber. Benefits of pectin supplementation include reduction of cholesterol, balance of glucose levels, improvement in glycemic control for diabetics, reduction of blood pressure, support for cardiovascular health, cancer prevention as well as an overall improvement in gastrointestinal health. [26]

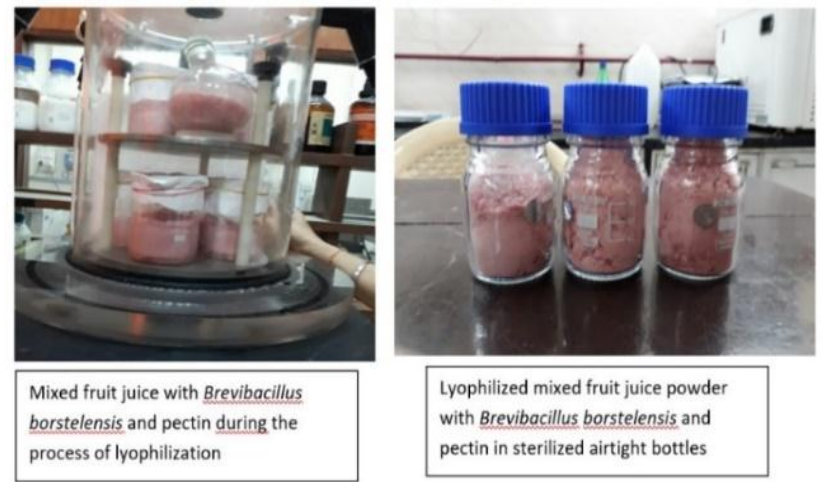

Figure 1: Lyophilized mixed fruit juice powde 
[2]. Analysis of the Nutraceutical:

\section{i. Shelf life studies:}

The lyophilized probiotic in the nutraceutical preparation retained its viability till six months at refrigeration $\left(4^{0} \mathrm{C}\right)$ and ambient temperature $\left(30^{\circ} \mathrm{C}\right)$ as shown in Figure 2.

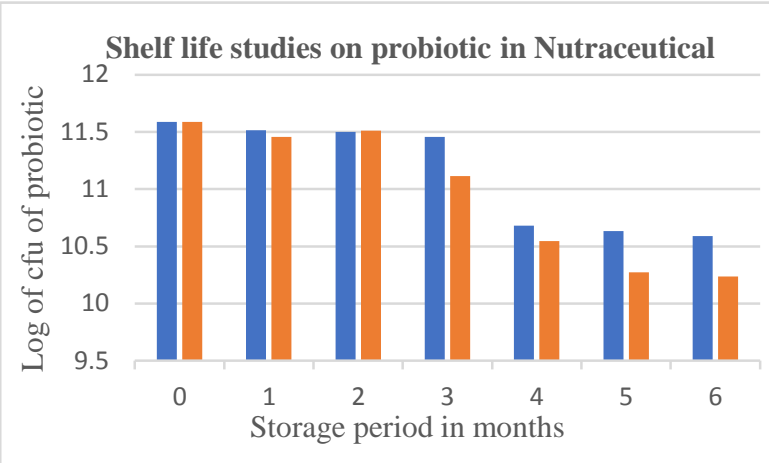

- Refrigeration temperature $\quad$ Room temperature

Figure 2: Graph showing viability of the probiotic in the nutraceutical powder

For up to two months, the viability was $3.2 \times 10^{11} \mathrm{cfu} / \mathrm{gm}$ almost equal to the initial count which was $3.8 \times 10^{11} / \mathrm{cfu} / \mathrm{g}$ irrespective of the storage temperature; which started declining subsequently till 6 months. Residual viability at the end of six months was $3.9 \times 10^{10} \mathrm{cfu} / \mathrm{g}$ which was much greater than the recommended minimum numbers at the end of shelf life. Foods containing probiotics should maintain the number of bacteria till the end of shelf life mentioned on the label, since the minimum recommended number of probiotic cells at the time of consumption should be at least $10^{6} \mathrm{cfu} / \mathrm{g}$ [27]. Since the product fulfils the requirement it can be safely stored between $4^{0} \mathrm{C}-30^{0} \mathrm{C}$ for six months.

\section{ii. Antibacterial activity:}

The nutraceutical was found to be more effective against Gram positive bacteria than Gram negative bacteria (Table 2). The diameter of zones of inhibition was directly proportional to the concentration of the nutraceutical powder. This may be due to higher cell number of the probiotic with increasing concentration of the nutraceutical. This shows that it can be used as a therapeutic agent against these pathogens during an infection

Some of the fruit juices exhibit significant antibacterial effect due to their mineral content such as iron and other biologically active substances [28]. Medicinal importance of fruit juices has been increasing and fruits have become valuable sources to maintain human health due to their therapeutic value [29]. Pomegranate contains polyphenols, tannins, ellagic acid and anthocyanins like delphinidins, cynanidins which have antimicrobial properties [30]
Table 2: Antibacterial activity

\begin{tabular}{|l|c|c|c|c|}
\hline & \multicolumn{4}{|c|}{ Zone of inhibition in mm } \\
\hline $\begin{array}{c}\text { Conc. Of } \\
\text { Nutraceutical } \\
\text { Test culture }\end{array}$ & $\begin{array}{c}62.5 \\
\mu \mathrm{g} / \mathrm{ml}\end{array}$ & $\begin{array}{c}125 \\
\mu \mathrm{g} / \mathrm{ml}\end{array}$ & $\begin{array}{c}250 \\
\mu \mathrm{g} / \mathrm{ml}\end{array}$ & $\begin{array}{c}500 \\
\mu \mathrm{g} / \mathrm{ml}\end{array}$ \\
\hline $\begin{array}{l}\text { Bacillus cereus NCIM 2109 } \\
\text { Bacillus subtilis ATCC 6633 }\end{array}$ & - & 11 & 14 & 20 \\
\hline $\begin{array}{l}\text { Brevibacterium casei } \text { MCC } \\
\text { 2029 }\end{array}$ & - & 11 & 12 & 16 \\
\hline Staphylococcus aureus & - & - & 09 & 14 \\
\hline Methicillin Resistant S. aureus & 11 & 12 & 13 & 19 \\
\hline Salmonella paratyphi B & - & - & - & - \\
\hline Salmonella abony & - & - & - & 08 \\
\hline Escherichia coli & - & - & - & - \\
\hline Key: -
\end{tabular}

Key: - = zone of inhibition equal to or lesser than $7 \mathrm{~mm}$

\section{iii. Nutrition profile:}

The nutraceutical sample was found to have an average energy value of $357.75 \mathrm{Kcal} / 100 \mathrm{~g}$, Total carbohydrates was $84.85 \mathrm{~g} / 100 \mathrm{~g}$, protein was $4.6 \mathrm{~g} / 100 \mathrm{~g}$, Vitamin $\mathrm{C}$ was $130.83 \mathrm{mg} / 100 \mathrm{~g}$, total fat and cholesterol were absent in the sample, the fatty acid profile showed less than $0.01 \%$ of saturated, monounsaturated and polyunsaturated and trans fatty acids.

The use of a nutraceutical-based treatment for hypercholesterolemia is increasing, and is considered to be an important preventive action to take when hypercholesterolemia is mild or moderate posing a low and/or moderate risk factor [31]. The prepared nutraceutical powder is a zero-cholesterol supplement, shows a good fatty acid profile and also proved to reduce cholesterol when tested.

The carbohydrate content of the powder is approximately $85 \%$ which may be the reason for the powder to give a high energy i.e. $356 \mathrm{Kcal} / 100 \mathrm{gm}$. The The protein content was $4.6 \%$, higher than fresh fruits, since the powder is a more concentrated form of the fruit solids due to dehydration. Moreover, there is no much loss of antioxidants as well as proteins due to process of freeze drying where high temperatures are not used. There was no reduction in nutritive value of the powder even after a month of storage.

iv. Chemical parameters:

Listed in Table 3

Water activity $\mathbf{a}_{\mathbf{w}}$

$\mathbf{a}_{\mathbf{w}}$ of the nutraceutical powder was found to be 0.154 . 
Maintaining a low water activity controls microbial growth, extends shelf life and allows safe storage of some products without refrigeration [32] Many powdered products can form cakes eventually if packaging is not proper. Hence, knowing the water activity can also help to decide the type of packaging required for a product to increase its shelf life.

Table 3: Chemical parameters

\begin{tabular}{|l|l|}
\hline Parameter & Result \\
\hline Water activity & 0.154 at $29.7^{\circ} \mathrm{C}$ \\
\hline Total soluble solids & $12 \%$ \\
\hline Colour & $\mathrm{L}=71.99, \mathrm{a}=12.18, \mathrm{~b}=7.35$ \\
\hline Bulk density & $0.28 \mathrm{~g} / \mathrm{ml}$ \\
\hline Tapped density & $0.38 \mathrm{~g} / \mathrm{ml}$ \\
\hline Carr index & 26.4 \\
\hline $\begin{array}{l}\text { Heavy metal contaminants } \\
\text { As, } \mathrm{Pb}, \mathrm{Hg}, \mathrm{Cd}\end{array}$ & $<0.1 \mathrm{mg} / \mathrm{kg}$ \\
\hline $\mathrm{pH}$ & 3.23 \\
\hline Titratable acidity & $0.512 \%$ (citric acid) \\
\hline
\end{tabular}

\section{The total soluble solids (TSS)}

TSS in the nutraceutical powder was determined using refractometer and was found to be $12 \%$. TSS is expressed as degrees Brix. The brix estimates all soluble solids like sucrose, fructose, vitamins, minerals, amino acids, proteins, hormones, etc. in the nutraceutical. Researchers have reported TSS in pineapple, apple, plum, orange and mango fruit as 9,12, 16, 10 and 20-degree Brix respectively [33]. Maintenance or slight increase in TSS content of the juice during storage is desirable for safeguarding good juice quality [34].

\section{Colour value}

When a colour is expressed in CIELAB, L* defines lightness, $a^{*}$ denotes the red/green value and $b^{*}$ the yellow/blue value. Since $\mathrm{L}^{*}$ scale value of the powder was 71.99 , it indicates the colour is light, $\mathrm{a} *$ scale value was 12 and this positive number indicates the sample is red and not green, b scale value was 7.35 , indicating that the sample is yellow and not blue. All three values are required to completely describe the colour of the powder. If the colour of the product prepared from fruits and vegetables are preserved even after the processing it indicates that the nutrients are also preserved. Since the nutraceutical powder was prepared by Lyophilization and not subjected to heat treatment after extraction, it may have preserved most if not all the nutrients.

\section{Tapped Bulk density and Bulk density}

The Hausner ratio is correlated to the flowability of a powder. It is calculated by the formula: $\mathrm{H}=$ Tapped density / Bulk density. A Hausner ratio greater than 1.25 is said to indicate poor flowability. The Tapped bulk density of the nutraceutical powder was found to be $0.38 \mathrm{gm} / \mathrm{ml}$. Its bulk density was $0.28 \mathrm{gm} / \mathrm{ml}$. The Hausner ratio of the powder $\mathrm{H}$ $=0.38 / 0.28=1.36$, which is higher than 1.25 , thus indicating poor flowability.
The Carr index is also said to measure flowability. Its formula is $\mathrm{C}=100 \times$ (1-Bulk density / Tapped density). A Carr index greater than 25 is said to have poor flowability. [35] The Carr index of the powder $\mathrm{C}=100 \times(1-0.28 / 0.38)=$ 26.4 , which is greater than 25 , confirming poor flowability. This may be due to its hygroscopic nature. The lyophilized nutraceutical powder needs to be stored in an airtight sterile container to maintain its flowability.

\section{Metal contaminants:}

Metals such as arsenic, lead, cadmium, mercury and others are found in certain foods. At high levels, these metals can be toxic, but eliminating them entirely from our food supply is not always possible because these metals have polluted our air, water and soil.

According to American National standard, 2008 and European Union Pharmacopoeia, 2010 the fixed cut off limits for lead in food is 10ppm, Arsenic is 5ppm, Cadmium it is $0.3 \mathrm{ppm}$. In Europe, the European Commission discussed the need for setting maximum levels of $\mathrm{Pb}, \mathrm{Cd}$, and $\mathrm{Hg}$ in food supplements to amend the Commission Regulation (EC) No. 1881/2006, because monitoring studies found high levels of these metals in certain food supplements. The following limits were then set: $3.0 \mathrm{mg} / \mathrm{kg}$ for $\mathrm{Pb} ; 1.0 \mathrm{mg} / \mathrm{kg}$ for $\mathrm{Cd}$ and $0.10 \mathrm{mg} / \mathrm{kg}$ for $\mathrm{Hg}$ [36].

The nutraceutical powder prepared from mixed fruit juice and probiotic had less than $0.1 \mathrm{mg} / \mathrm{kg}$ of all four heavy metals tested, $\mathrm{Hg}, \mathrm{Cd}, \mathrm{Pb}$ and As. All are within acceptable limits. The powder thus does not pose a potential health hazard in terms of heavy metal toxicity.

\section{pH and Titratable acidity:}

pH of the reconstituted nutraceutical powder measured with the help of $\mathrm{pH}$ meter was found to be 3.23. The presence of organic acids like citric acid, lactic acid, malic acid and tartaric acids in fruit juices lowers the $\mathrm{pH}$ of these juices. This acts as a natural preservative for the juice. This will also give the tart flavour to the reconstituted powder, a favourable organoleptic property of the nutraceutical preparation.

The titratable acidity of fruits is used, along with sugar content, as an indicator of maturity, generally the higher the maturity, the lower the acid content. The acidity of a fruit juice avoids alteration of its organoleptic nature and fermentation processes.

Acidity was calculated in terms of citric acid since this is the predominant organic acid in citrus fruits, and in pineapple and pomegranate.

$$
\text { Acidity }=0.512 \%(\mathrm{w} / \mathrm{w}) \text { of nutraceutical powder }
$$

\section{v. Cholesterol reduction assay:}

The probiotic culture Brevibacillus borstelensis was able to reduce cholesterol when incubated with it for 24 hours to the 
extent of $34 \%$ and the nutraceutical containing the probiotic culture reduced cholesterol by $25 \%$. [Table 4]

Table 4: Reduction of cholesterol by the probiotic and nutraceutical formulation

\begin{tabular}{|l|l|l|}
\hline Test sample & $\begin{array}{l}\text { Residual } \\
\text { Concentration of } \\
\text { cholesterol in } \\
\mu \mathrm{g} / \mathrm{ml}\end{array}$ & $\begin{array}{l}\text { Reduction in } \\
\text { cholesterol in } \\
\text { supernatant } \\
\mu \mathrm{g} / \mathrm{ml}\end{array}$ \\
\hline Control & 99.02 & --- \\
\hline Brevibacillus borstelensis & 65 & 34.02 \\
\hline Nutraceutical & 73.82 & 25.2 \\
\hline
\end{tabular}

The nutraceutical powder prepared by lyophilization contains spores (dormant forms) of Brevibacillus borstelensis, which after inoculation into the Rogosa broth after a time lag would germinate into vegetative cells of the culture. These vegetative cells are metabolically active and begin to metabolize cholesterol. Hence during the 24-hour incubation, the young culture of Brevibacillus borstelensis could reduce more cholesterol than the nutraceutical sample.

The bile salt hydrolase activity of probiotics has been associated with their cholesterol lowering properties [37]. One of the probable mechanisms used by this bacterium to reduce cholesterol appears to be deconjugation of bile salts, since it was also found to be positive for bile salt hydrolase activity. The manifestation of cardiovascular disease can be reduced in individuals suffering from hypercholesterolemia, if total and in particular LDL cholesterol can be controlled with use of the right probiotic supplements. This method could be effective in dealing with coronary heart disease [38].

\section{vi. Microbiological safety}

The nutraceutical was devoid of aerobic mesophiles except the probiotic Brevibacillus borstelensis. Neither coliforms, nor yeasts or moulds were detected in the sample. Spoilage causing organisms were ruled out from the preparation. Pathogens like Staphylococcus aureus, Salmonella species, Shigella species, Vibrio cholerae, Clostridium perfringens were absent when tested. The sample therefore proved to be safe for consumption.

\section{CONCLUSION}

The mixed fruit juice-based nutraceutical powder containing the novel probiotic culture, Brevibacillus borstelensis was good in terms of nutritional profile, antibacterial activity and cholesterol reducing ability. It proved to be a suitable carrier for the probiotic culture, and was safe for consumption by lactose intolerant population. Lyophilization helped to improve the shelf stability of the product, apart from retaining nutrients and improving the viability of the probiotic. It was also found to be safe for consumption as per FSSAI microbiological safety tests.

Future studies will aim at including multiple probiotic cultures each exhibiting unique health benefits in the formulation and improving the consistency of the powder in terms of its hygroscopic nature and converting it to a freeflowing powder for its optimal storage and use.

\section{ACKNOWLEDGMENT}

This work was partially funded by University of Mumbai. We would also like to express our gratitude to CIRCOT, Mumbai for the lyophilization facility and Enviro Care Labs Pvt Ltd for analyzing the nutraceutical.

\section{REFERENCES}

[1]. E. K. Kalra, "Nutraceutical-definition and introduction," AAPS Pharm Sci, vol. 5, no. 3, pp. 27-28, 2003.

[2]. R. K. Keservani, R. K. Kesharwani, N. Vyas, S. Jain, R. Raghuvanshi, and A. K. Sharma, "Nutraceutical and functional food as future food: a review," Der Pharmacia Lettre, vol. 2, pp. 106-116, 2010

[3]. R. P. Singh, K. N. C. Murthy, and G. K. Jayaprakasha, "Studies on the antioxidant activity of pomegranate (Punica granatum) peel and seed extracts using in vitro models," Journal of Agricultural and Food Chemistry, vol. 50, no. 1, pp. 81-86, 2002

[4]. J. S. Jurenka, "Therapeutic application of pomegranate (Prunus granatum L.) A review." Alternative Medicine Review. 13 (2): 128-144, 2008.

[5]. S. M. D Khan, V. Ravikumar, and K. Neelima,. "Pharmacological intervention of the fruit of plant Ananas comosus acting as wound healing agent in various animal models International." Journal of Pharmacy and Technology. 3 (1): 1807-1824, 2011

[6]. J.T. Peterson, Dwyer, G.R. Beecher, Bhagwat, S.E. Gabhardt, S.E. Haytowitz, J.M Holden. "Flavanones in oranges, tangerines (mandarins), tangors and tangelos: A compilation and review of the data from the analytical literature." J. Food Compos. Anal.;19:S66-S73. doi: 10.1016/j.jfca.2005.12., 2006

[7]. L. G. Marques, M. C. Ferreira, J. T. Freire, "Freeze-Drying of Acerola (Malpighia glabra L.)". Chemical Engineering and Processing, v. 46, n. 5, p. 451-457, 2007

[8]. M. Fazaeli, Z. Emam-Djomeh, Ashtari, M. Omid "Effect of spray drying conditions and feed composition on the physical properties of black mulberry juice powder." Food and Bioproducts Processing 90: 667-675, 2012

[9]. N Shofian, Hamid, A. Osman , N. Saari , F. Anwar , M. Pak Dek ,M. Hairuddin "Effect of Freeze Drying on the Antioxidant Compounds and Antioxidant Activity of Selected Tropical Fruits". Int. J. Mol. Sci. 12 (7); 4678-4692, 2011

[10]. J.Z. Xiao, S. Kondo, N. Takahashi, et al. "Effects of milk products fermented by Bifidobacterium longum on blood lipids in rats and healthy adult male volunteers." Journal of Dairy Science. 2003;86(7):2452-2461.

[11]. J. W. Anderson, S. E. Gilliland. "Effect of fermented milk (yogurt) containing Lactobacillus acidophilus L1 on serum cholesterol in hypercholesterolemic humans." Journal of the American College of Nutrition.;18(1):43-50, 1999

[12]. M. E. Sanders "Evidence that Probiotics can Improve Cholesterol Levels." California Dairy Research Foundation, Feb 2018 
[13]. A. S. Nair, A. V. Dubhashi "In-vitro Transit Tolerance of Probiotic Bacillus species in Human Gastrointestinal Tract" International Journal of Science and Research (IJSR) Volume 5 Issue 6, 1899-1902, June 2016

[14]. R.C. Ray \& P.S. Sivakumar "Traditional and novel fermented foods and beverages from tropical root and tuber crops: review. " International Journal of Food Science \& Technology, 44(6), 1073-1087, 2009

[15]. B. Pakbin, S.H. Razavi, ; R Mahmoudi,P. Gajarbeygi, "Producing Probiotic Peach Juice". Biotechnol. Health Sci.2014, 1, 1-5.

[16]. De Souza Neves Ellendersen, L.; Granato, D.; K.B Guergoletto, G. Wosiacki. "Development and sensory profile of a probiotic beverage from apple fermented with Lactobacillus casei." Eng. Life Sci. 12, 475-485. 2012

[17]. A.L.F. Pereira, T.C. Maciel,; S. Rodrigues, "Probiotic beverage from cashew apple juice fermented with Lactobacillus casei." Food Res. Int., 44, 1276-1283. 2011

[18]. R.D.C.S. Ranadheera, , S.K. Baines, and M.C. Adams. Importance of food in probiotic efficacy. Food Res. Int. 43: 1-7., 2010.

[19]. K. K. Kondepudi, \& N. Sharma, \& N. Gupta . "Screening of Ethnic Indian Fermented Foods for Effective Phytase Producing Lactic Acid Bacteria for Application in Dephytinization of Phytate Rich Foods." International Journal of Scientific Research. 6. 1-7. 10.26438/ijsrbs/v6i2.17, 2019

[20]. C. Perez, M. Paul and P. Bazerque, "An antibiotic assay by the agar well diffusion method", Acta Biol. Med. Exp., 15, 113-115, 1990

[21]. A. L. Cavalcanti, K. F. Oliveira, P. S. Paiva, M.V.D. Rabelo, S.K.P. Costa, FF Vieira. "Determination of total soluble solids (Brix) and $\mathrm{pH}$ in milk drinks and industrialized fruit juices". Pesq Bras Odontoped Clin Integr; 6:57-64., 2006

[22]. Hunter, S. Richard, and Harold, W.Richard; The Measurement of Appearance, 2nd ed., John Wiley and Sons, Inc. New York, NY USA, 1987

[23]. FSSAI Manual of Methods of Analysis of Foods, Microbiological Testing, Vol 14, 2012

[24]. Meera, Sajag Ved and S. Ajay Vino. "Development of Value Added Probiotic Freeze-Dried Papaya Juice Powder" Journal of Food Product Development And Packaging Volume 3 Pages 0111,2016

[25]. A.Y. Tamine and RK. Robinson. Yogurt: Science and Technology. CRC Press, New York: NY, 2007

[26]. S. Summer, The Ins \& Outs of Pectin, 05.02.16 Nutraceuticals World

[27]. C. Stanton, C. Desmond M. Coakley, JK Collins, G. Fitzerand, $\mathrm{RP}$, Ross . Challenges facing development of probiotic containing functional foods. In: Franworth, E.R. (Ed.), Handbook of Fermented Functional Foods. CRC Press, Boca Raton, USA, pp. 27-58, 2003

[28]. D.S, Chavan. M.D: "Studies on antimicrobial activty and phytochemical analysis of citrus fruit juices against selected enteric pathogens". International Research Journal of Pharmacy.; 3(11). 2012

[29]. Sara Jelodarain, A.H. Ebrahimanbadi, F.J. Kashi: "Evaluation of antimicrobial activity of Malus domestica fruit extract from Kashan area." Avicenna Journal of Phytomedicine.; 3(1), 2013
[30]. S. Kote, S. Kote, L. Nagesh . "Effect of Pomegranate Juice on Dental Plaque Microorganisms (Streptococci and Lactobacilli)." Ancient Science of Life. 31(2):49-51. 2011

[31]. R Volpe, G. Sotis . "Nutraceuticals: definition and epidemiological rationale for their use in clinical practice." High Blood Pres Cardiovasc Prev 22: 199-201, 2015

[32]. M. E. Doyle and K. Glass. "Spores of Clostridium botulinum in Dried Dairy Products," Food Research Institute, 2013.

[33]. C. K. Sahni, D.S. .Khurdiya "Physicochemical changes during ripening in 'Dashehari' 'Chausa' 'Neelum' and 'Amrapali' mango." Indian Food Packer, 5-10. 1989

[34]. R. J. Bhardwaj,, and S. Pandey.. "Juice blends-a way of utilization of under-utilized fruits, vegetables, and spices: a review". Crit. Rev. Food Sci. Nutr. 51:563-570, 2011

[35]. Vinnie Hebert, Brookfield Ametek "Tracking Bulk Density to Maximize Tablet Production.," Tablets and Capsules, March 2016

[36]. EU Commission Regulation EC No. 629/2008

[37]. M. L. Jones, C.J. Martoni, M. Parent, and S. Prakash "Cholesterol-lowering efficacy of a microencapsulated bile salt hydrolase-active Lactobacillus reuteri NCIMB 30242 yoghurt formulation in hypercholesterolaemic adults." Br. J. Nutr. 107, 1505-1513, 2012

[38]. M. A Fradi, M.. Drissa, Cheour, I. Meddeb, H. Drissa "Coronary atherosclerosis and familial hypercholesterolemia: A case report" Tunis. Med., 86, pp. 200-202, 2008m

\section{AUTHORS' PROFILE}

Dr. Aparna V. Dubhashi is an Associate Professor in Microbiology Department, G. N Khalsa College, Matunga, (Autonomous), Mumbai. She has undergraduate teaching experience of 24 years and post graduate teaching experience of 18 years. She is recognised as $\mathrm{PhD}$ guide in subjects, Microbiology and Bioanalytical Sciences and is currently guiding $6 \mathrm{PhD}$ scholars.

Mrs. Ajitha S. Nair is an Associate Professor [(MSc in Microbiology, NET (Life Sciences)] in the Department of Microbiology, S.I.W.S. N.R. Swamy College, Wadala, Mumbai, affiliated to University of Mumbai. She has a teaching

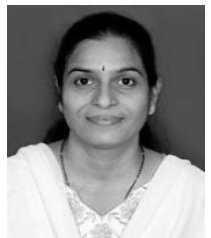
experience of 24 years and is pursuing her $\mathrm{PhD}$ in Microbiology from G.N. Khalsa College, an autonomous institution, under the guidance of Dr. Aparna V. Dubhashi. 